\title{
Life CyCle Costing Model FoR THE MEMBRANE System Nur Syamimi Jiran*
}

Department of Materials, Manufacturing and Industrial Engineering, School of Mechanical Engineering, Faculty of Engineering, Universiti Teknologi Malaysia

Malaysia

\section{Muhamad Zameri Mat Saman}

Department of Materials, Manufacturing and Industrial Engineering, School of Mechanical Engineering, Faculty of Engineering, Universiti Teknologi Malaysia

Malaysia

\section{Noordin Mohd Yusof}

Department of Materials, Manufacturing and Industrial Engineering,School of Mechanical Engineering, Faculty of Engineering, Universiti Teknologi Malaysia

Malaysia

*Corresponding author's Email: mimi_2687@hotmail.com

\section{Author's Biography}

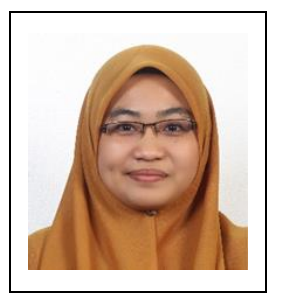

Nur Syamimi Jiran received her Bachelor and Master degree in Industrial Engineering from Universiti Teknologi Malaysia (UTM). She is currently a PhD student in the Department of Materials, Manufacturing and Industrial Engineering at UTM. Her research interests include sustainability assessment, life cycle costing and industrial engineering. Mrs Jiran is holding a Graduate Engineer role from the Board of Engineer Malaysia and a graduate member of the Institution of Engineer Malaysia.

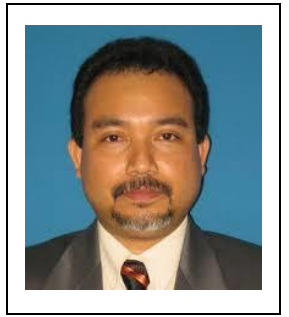

Muhamad Zameri Mat Saman received his bachelor degree in Mechanical Engineering (Industrial Engineering) from UTM, Master degree in Advanced Manufacturing System Engineering and a PhD in Mechanical Engineering from Coventry University, UK. His current research interests are sustainable development, product life cycle, manufacturing system and industrial engineering. He is a Professor at School of Mechanical Engineering, Faculty of Engineering, UTM and a director at University Laboratory Management Unit, UTM. He had published plenty of research articles, book chapter and journal paper, supervised more than 20 Masters and PhD students, lead 6 research projects and produce 8 copyrights.

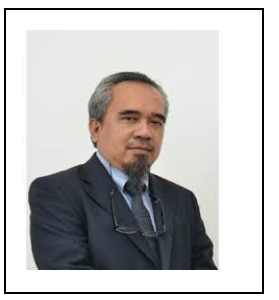

Noordin M. Yusof received his bachelor degree in Mechanical Engineering from UTM, Master degree in Advanced Manufacture Technology from Canfield Institute of Technology, UK and a PhD in Mechanical Engineering from UTM. His current research area is machinability studies, hard turning and operations management. He is a Professor at School of Mechanical Engineering, Faculty of Engineering, UTM. He had published plenty of research articles, review articles, journal paper with other organizations. and a book chapter. He is actively involved in innovation activity and consultancy 


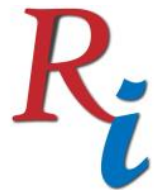

\section{Asia Proceedings of Social Sciences \\ (APSS) \\ www.readersinsight.net/APSS}

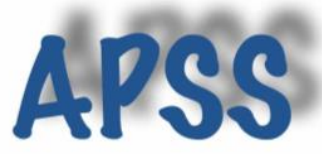

\section{Re se a r ch H i g h I igh t s}

Computerized cost estimation though cost model help user to estimating product cost since the early stage of product development. Total product cost is an economic indicator that a sustainable product promotes a good impact on the environment but also contribute a profit increased to the organization. In addition, the cost model could be a decision-making tool for the organization in selecting alternatives to replace the older system in term of financial and other benefits offered by the new technology. The proposed cost model helps membrane user to select the lower membrane system's cost during its complete lifespan and it helps management to rearrange the production line and filtering system in reducing the total cost. Activity-based costing ( $\mathrm{ABC}$ ) useful to estimating the overhead cost, the total cost of the membrane system and also other useful information in improving the whole membrane system.

\section{Graphical A bstract}

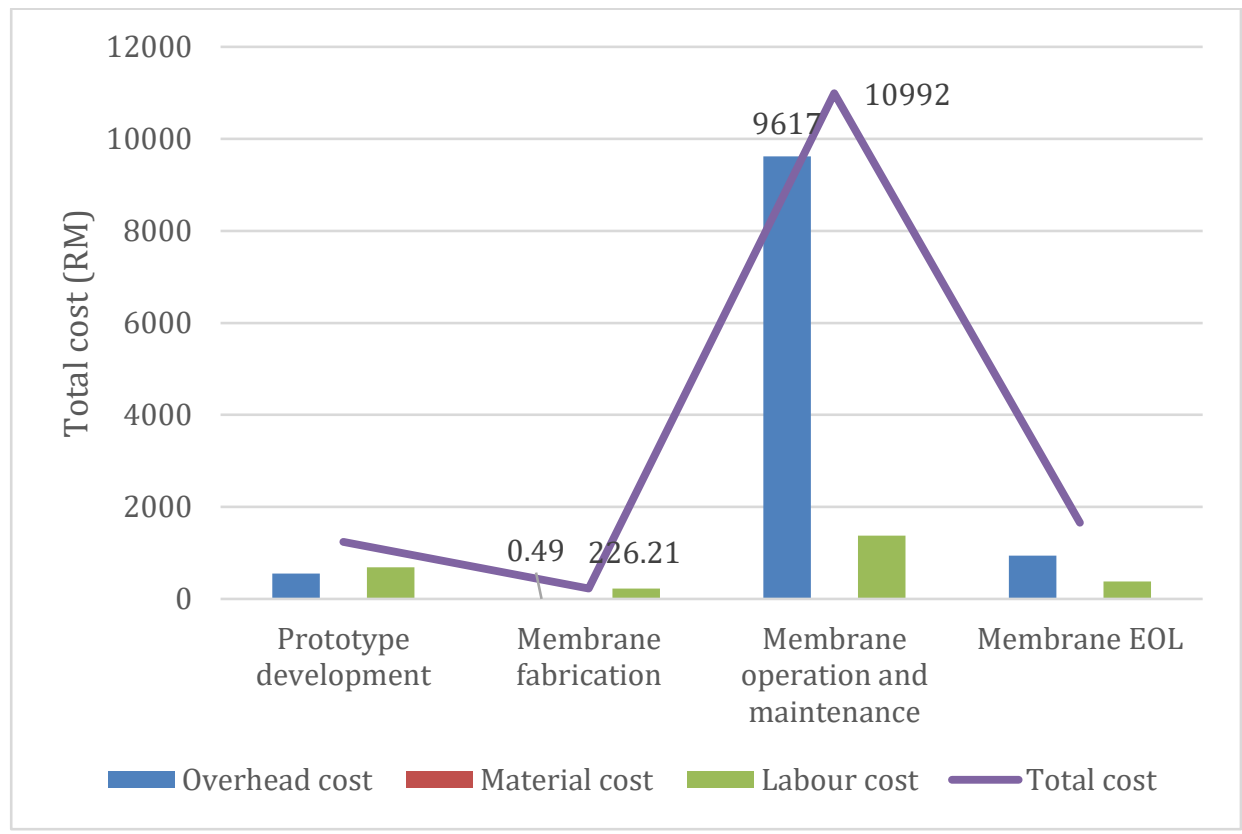

\section{Research Objectives}

Manual or computerized economic assessment is important to prove that sustainable product have an environmental and economic benefit to the organization (Hemdi, 2012) and it helps to expose unexploited benefits of new technology (Settani, 2008). But, manual cost estimation is a tough, complicated and time-consuming process. Thus, this research aim to develop the cost model of the membrane system to make the cost estimation process as an easier and simpler process. So, membrane user could estimate the cost since the early stage of membrane development or during the design stage because it saved up to $85 \%$ of total product cost (Dowlatshahi, 1992). The result cost model could be a justification tool in term of the financial aspect, showing monetary flows and other relevant benefits. In addition, the cost model could be a decision makers tool to choose several membrane system's options based on the economic aspect. 


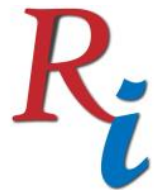

\section{Asia Proceedings of Social Sciences \\ (APSS) \\ www.readersinsight.net/APSS}

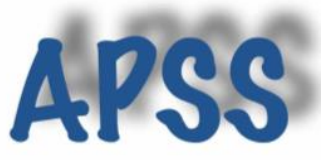

\section{Methodology}

ABC method is a detail cost estimation technique used to calculate the total cost of the membrane system because it used detail process information to estimate the overhead cost (Xu, Fernandez and Njuguna, 2014). Thus, it has the ability to accurately deal with process information to allocate the overhead costs (Esmalifalak, Albin and Benzadpoor, 2015). Derived equations used to calculate the total cost is stored in Microsoft Excel than it will be linked to Microsoft Visual Basic that visualised the cost model in a form of graphical user interface (GUI). The cost model is a set of assumption, rules, equations and variables to describes the system in term of economic view (Giudice et al., 2006). GUI of cost model named LCC Tool is a tool that aid user in estimating the membrane cost in a faster way without the need to deal with multiple equations but able to produce accurate cost result. A case study of determining the life cycle cost of hollow fiber membrane module (HFMM) is used to measure the model capability in estimating the total cost.

\section{Results}

The LCC value of the membrane system is as follows, RM1237.53, RM226.21, RM10992.00 and RM1660.87 for all stages respectively. The result shows that the cost of manufacturing the HFMM is the cheapest cost but the cost of membrane operation contribute to the highest cost compared to other stages. As the LCC tool used ABC as a cost estimation technique, it shows that cost of the development of membrane prototype is the highest cost compared to other activity during the membrane lifespan. Besides, water filtration and chemical cleaning activity during the membrane operation and maintenance is known as among the highest cost. Apart from highlighting the highest cost activity, through $\mathrm{ABC}$ analysis, an activity that contributes less cost could identify such as fiber collecting, fiber cleaning and bottle storage for a degassed process during the membrane fabrication. Besides that, resource space is considered as the highest cost at all stages. Therefore, relocating the manufacturing factory could further reduce the total cost of the membrane system. In addition, setup and water are recognised as the lowest consumed resource.

\section{Findings}

The LCC tool helps to identify the LCC value and also reveal most consumption resource and highest cost which is an useful information for the team to cut the total cost. The LCC value of the membrane system is RM1237.53, RM226.21, RM10992.00 and RM1660.87 for prototype development, membrane fabrication, membrane operation and membrane replacement stage respectively. The highest cost comes from the membrane operation phase while membrane fabrication is the lowest cost phase. Space is highlighted as the most spent resources throughout the membrane lifespan while setup resource is the lowest consumed resources.

\section{Acknowledgement}

The first author would like to thank the Ministry of Education, Malaysia for sponsoring her study under MyPhD scholarship.

\section{References}

Dowlatshahi, S. (1992). Product design in a concurrent engineering environment: an optimization approach. International Journal of Production Research, 30(8), 1803-1818. doi: 10.1080/00207549208948123 


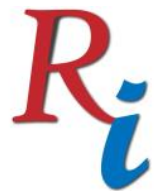

\section{Asia Proceedings of Social Sciences \\ (APSS) \\ www.readersinsight.net/APSS}

Esmalifalak, H., Albin, M. S., \& Behzadpoor, M. (2015). A comparative study on the activity based costing systems: Traditional, fuzzy and Monte Carlo approaches. Health Policy and Technology, 4(1), 58-67. doi: https://doi.org/10.1016/j.hlpt.2014.10.010

Hemdi, A. R. (2013). Fuzzy based sustainability indicator for product design and development process. Universiti Teknologi Malaysia.

Life Cycle Cost Analysis. (2006). In Giudice, F., La Rosa, G., and Risitano, A. (Ed.), Product Design for the Environment A Life Cycle Approach (pp. 111-134): CRC Press.

Settanni, E. (2008). The need for a computational structure of LCC. The International Journal of Life Cycle Assessment, 13(7), 526-531. doi: 10.1007/s11367-008-0036-6

Xu, Y., Fernandez S. J., \& Njuguna, J. (2014). Cost modelling to support optimised selection of End-of-Life options for automotive components. The International Journal of Advanced Manufacturing Technology, 73(1), 399-407. doi: 10.1007/s00170-014-5804-9 